\title{
Sardegna, Tradução e Interculturalidade
}

\author{
Susi Leolinda Rosas Queiroz ${ }^{*}$ \\ Alessandra Paola Caramori
}

RESUMO: O presente trabalho, partindo da realização de uma tradução comentada, tem o propósito de refletir sobre questões práticas do processo tradutório, assim como sobre o público a que se destina. Considerando a perspectiva funcionalista dos estudos da tradução, foi analisado o capítulo "Sardegna" do livro infantil Italia storie, ballate e racconti do escritor italiano Roberto Piumini. Foram também abordados os conceitos de estrangeirização e domesticação propostos pelo teórico Lawrence Venuti ao discutir o objetivo principal deste trabalho: fazer conhecer ao público brasileiro um pouco da Itália através de suas regiões e de personagens importantes de sua cultura. A perspectiva da mediação cultural foi então decisiva para conduzir as escolhas do tradutor, incluindo sua opção por uma tradução comentada e por sua apresentação bilíngue.

PALAVRAS-CHAVE: Literatura infantojuvenil; Tradução; Roberto Piumini; Sardenha.

ABSTRACT: Il presente lavoro, partendo dalla realizzazione di una traduzione commentata, ha lo scopo di riflettere sulle questioni pratiche del processo traduttologico, cosí come sul pubblico a cui si rivolge. Al considerare la prospettiva funzionalista degli studi della traduzione, è stato analizzato il capitolo "Sardegna" del libro per bambini Italia: storie, ballate e racconti dello scrittore italiano Roberto Piumini. Abbiamo trattato anche dei concetti di estraniamento e addomesticamento proposti dal teorico Lawrence Venuti al discutere l'obiettivo principale di questo lavoro: far conoscere al pubblico brasiliano un po'dell'Italia attraverso le sue regioni e i personaggi importante della sua cultura. La prospettiva della mediazione culturale è stata decisiva per condurre le scelte del traduttore, incluso anche l'opzione per una traduzione commentata e per uma presentazione bilingue.

* Universidade Federal da Bahia, Salvador, Bahia (Brasil) susirosas@yahoo.com.br / apccaramori@ufba.br 
PAROLE CHIAVE: letteratura per l'infanza; traduzione; Roberto Piumini; Sardegna.

ABSTRACT: Starting from the carrying out of a commented translation, this paper aims to reflect on practical issues of the translation process, as well as the public it is destined for. Considering the functionalist perspective of the Translation Studies, we analyzed the chapter "Sardegna" from the children's book Italia storie, ballate e racconti, written by the Italian writer Roberto Piumini. We also considered the concepts of foreignization and domestication, proposed by the theorist Lawrence Venuti, when discussing the main objective of this study: to get Brazilian public in contact with a little more about Italy through its regions and through important characters of its culture. The perspective of cultural mediation was then crucial to conduct the choices of the translator, including the option for a commented translation and for its bilingual presentation.

KEYWORDS: children's literature; translation; Roberto Piumini; Sardinia. 


\section{Introdução}

A tradução não apenas possibilita o acesso a um texto produzido em uma língua desconhecida, como cria pontes entre culturas. Estamos mergulhados num processo acelerado de internacionalização global, quebra de fronteiras e redução de distâncias, então estas pontes se fazem cada vez mais necessárias para a construção de um pensamento intercultural.

Este artigo é parte de uma pesquisa realizada no Instituto de Letras da UFBA. Para o trabalho foi realizada a tradução comentada de três capítulos do livro Italia: storie, ballate e racconti, de Roberto Piumini, para então refletir sobre a prática da tradução, abordando questões como a tradução de literatura infantil em prosa e poesia e os recursos para realizar a mediação cultural. Como, no livro supracitado, cada capítulo corresponde a uma região da Itália, foi eleito um representante para cada ponto do mapa: Liguria, retratando o norte; Abruzzo, o centro e Sardegna, o sul. Dado o pouco espaço de que dispomos, realizamos aqui um novo recorte, selecionando apenas um capítulo, Sardegna, para tecer comentários com ênfase na proposta intercultural relacionada ao processo de tradução.

Estando o imaginário brasileiro sobre a Itália relacionado geralmente a lugares como Roma, Florença e Veneza, julgamos pertinente selecionar um capítulo que desviasse um pouco do roteiro 
turístico tradicional. A Sardenha nos pareceu uma boa aposta: o conto apresenta construções locais muito características, além de mostrar uma personalidade importante da região e pouco conhecida pelos brasileiros: a escritora Grazia Deledda - mulher nascida na Sardenha, que conquistou o prêmio Nobel de Literatura em 1926.

\section{Traduzindo a Sardenha}

O livro Italia storie, ballate e racconti, do escritor italiano Roberto Piumini, é uma espécie de guia de viagem infantojuvenil. Publicado em 2013 pela Sillabe, editora especializada em livros de arte, faz parte de um projeto, intitulado In viaggio s'impara, que tem por objetivo levar o tema arte para as crianças de modo fruitivo e divertido. O projeto, que apresenta livros sobre literatura, teatro, história, viagens etc, está vinculado à linha editorial, Tempo libero by sillabe, dedicada a guias de cidades.

Segundo a editora Barbara Galla, em conversa por e-mail, a proposta do livro era apresentar às crianças obras de arte que normalmente estão fechadas em museus, assim como monumentos e belas paisagens que se encontram em cidades mais distantes. E para tal tarefa, convidaram o escritor Roberto Piumini por sua grande experiência como criador de belas narrativas - não só para crianças - e seu prestígio como comunicador, criando histórias que estimulam a imaginação e a curiosidade do leitor.

Piumini, considerado o herdeiro de Gianni Rodari, tem quase quinhentos livros publicados entre romances, fábulas, contos e poesias. Muitos dos seus livros já foram traduzidos para cerca de cinquenta idiomas. Seu trabalho tem uma viva relação com a oralidade, herança da presença constante do contar histórias em sua infância. Apresenta-se em espetáculos de leitura e recitação dos seus textos, envolvendo animação, teatro e música, pois acredita que a criança deseja a presença física do narrador. Foi considerado, pelos jornais La Stampa e La Repubblica, o escritor italiano mais produtivo do século XXI. Italia storie, ballate e racconti (2013) está entre suas publicações mais recentes.

Em suas 111 páginas, Italia storie, ballate e racconti, passeia por toda a Itália por versos e prosas, acompanhados pelas belas imagens de Giulia Servello. Como já foi dito anteriormente, cada capítulo é dedicado a uma região e tem como guia um personagem famoso que volta a ser criança. As personagens tem relação direta com os lugares, assim, a cidade de Verona, no capítulo Veneto é apresentada pela pequena Giulietta (Giulietta Capuleti), Aquila, em Abruzzo, pelo pequeno Gabriele (Gabriele D’Annunzio), a Sardegna, pela pequena Grazia (Grazia Deledda), 
assim como a lenda da fundação de Roma, no capítulo Lazio, é narrada por Rea (Rea Silvia da lenda de Rômulo e Remo), entre outros.

$\mathrm{Na}$ apresentação do livro, o autor revela o prazer de viajar e contar os lugares vistos, ouvidos e vividos que será compartilhado com o leitor até a última página:

Mi piace viaggiare, visitare luoghi, regioni, città.

Mi piace la natura, e dove vive la gente.

Mi piace, viaggiando, tenere gli occhi e le orecchie aperti:

vedere, ascoltare, imparare.

Mi piace conoscere la storia di luoghi, persone, costruzioni, opere, segni, nomi.

Mi piace viaggiare solo, ma ancora di più in compagnia.

In questo viaggio, regione per regione, mi accompagna un bambino della mia età.

Nessun bambino è un bambino qualsiasi, ma quelli che mi

fanno da guida sono bambini davvero speciali.

Mi piace, infine, raccontare i miei viaggi.

Si può raccontare con immagini e con parole, e io lo faccio.

Quanto alle parole, si può raccontare in prosa o in poesia.

Ho scelto di farlo in tutti e due i modi: così il racconto

sarà vario e mosso, proprio come è il viaggio. ${ }^{1}$ (PIUMINI, 2013, p. 5)

Ao tomarmos conhecimento do projeto da editora Sillabe, pensamos em dar acesso também aos nossos pequenos (e grandes) leitores para embarcar nessa viagem.

A escolha do capítulo a ser comentado não foi uma tarefa fácil, pois cada região tem um encanto que merece ser contado. Optamos por um escrito em prosa, visto que a tradução de poesia suscitaria uma nova discussão. Desse modo, o eleito foi o capítulo Sardegna ${ }^{2}$. Através desse conto, o leitor entra em contato, por exemplo, com os nuragues, construções de pedras típicas da ilha, e conhece a pequena Grazia, a escritora Grazia Deledda, que quer ser escritora quando crescer e é quem oferece algumas versões sobre o surgimento dos nuragues.

Para guiar as escolhas tradutórias, nos valemos, como suporte teórico, de princípios da teoria dos escopos, desenvolvida pelo linguista Hans J. Vermeer. De acordo com a teoria de Vermeer (1986), mais tarde desenvolvida com Katharina Reiss (REISS; VERMEER, 1996), a tradução

1 Gosto de viajar, visitar lugares, regiões, cidades./ Gosto da natureza e de onde vivem as pessoas./ Gosto, viajando, de manter os olhos e os ouvidos abertos:/ ver, ouvir, aprender./ Gosto de conhecer a história de lugares, pessoas,/ construções, obras, signos, nomes./ Gosto de viajar sozinho, mas gosto ainda mais em companhia./ Nesta viagem, região por região, me acompanha uma criança da minha idade./ Nenhuma criança é uma criança qualquer, mas aquelas que/ são meus guias, são realmente especiais./ Gosto, enfim, de contar minhas viagens./ Pode-se contar com imagens e com palavras, e assim o faço./ Quanto às palavras, pode-se contar em prosa ou em poesia./ Escolhi usar os dois modos: assim o contar/ será diversificado e movimentado, exatamente como é a viagem. (Tradução Nossa)

$2 \mathrm{O}$ capítulo completo e nossa tradução para o português brasileiro encontram-se no apêndice deste artigo. 
é realizada com um propósito - o escopo - e, para alcançá-lo, o tradutor dependerá do encargo tradutório, ou seja, elementos tais como emissor, receptor, tema, conteúdo, meio, lugar que conduzirão as escolhas tradutória (MORINI, 2007). Considerando a abordagem funcionalista da tradução, as estratégias definidas para traduzir o capítulo Sardegna foram, então, orientadas de acordo com o público-alvo, o meio onde seria veiculado e os objetivos do texto traduzido.

O público alvo seria, inicialmente, a criança com faixa etária média de 10 anos, classificado por Coelho (2000) como o leitor fluente, que está consolidando o domínio sobre a leitura e a compreensão do universo expresso. A autora sugere princípios orientadores para a escolha do livro adequado para cada tipo de leitor, associado à faixa etária, mas salienta que essas são indicações aproximativas, já que os parâmetros de categorização são subjetivos: "inter-relação entre sua idade cronológica, nível de amadurecimento biopsíquico-afetivo-intelectual e grau ou nível de conhecimento/ domínio do mecanismo da leitura" (COELHO, 2000, p. 32). O livro seria, então, indicado para o leitor fluente porque, ao objetivar a apresentação de uma cultura diferente, é importante que o leitor seja capaz de refletir e criar pontes, observando semelhanças e diferenças entre a cultura apresentada e a sua.

É importante lembrar, porém, que, para esta história chegar até o leitor infantil, é necessário a mediação de um adulto, geralmente os pais, responsáveis ou professores. No entanto, acreditamos no interesse do público adulto, não apenas como mediador, mas como um curioso seduzido pela própria história e seu caráter de interculturalidade. Deste modo, a tradução poderia ainda ser utilizada como material didático em cursos de línguas, ou em escolas bilíngues, destinada a um público de qualquer idade. Por isso a decisão de uma apresentação bilíngue: os textos em língua italiana e língua portuguesa lado a lado no mesmo espaço, para que possam ser visualizados juntos.

Seguindo com os elementos norteadores das estratégias, outro ponto fundamental é o meio onde o texto será veiculado. Estando restrito ao âmbito acadêmico, pudemos desfrutar de maior liberdade nas decisões tradutórias que frequentemente são coibidas pelo mercado editorial. Foi possível, inclusive, reproduzir as ilustrações do livro, pois a lei dos direitos autorais (Lei $\mathrm{n}^{\circ}$ 9.610/98, Art. 46) prevê o uso de imagens ou trechos de obras para fins acadêmicos com suas devidas indicações de autoria.

Por fim, o escopo da tradução consistiu no favorecimento de pontes culturais BrasilItália (VENUTI, 1998). Desse modo, buscamos conduzir o leitor para mais perto da cultura estrangeira, o que nos leva, inevitavelmente, à estratégia de estrangeirização proposta pelo 
teórico americano Lawrence Venuti. De acordo com Venuti (2002), a estrangeirização consiste em deixar referências estrangeiras na tradução, de modo que o leitor perceba que se trata de uma reescrita de um texto suscitado em outra cultura. Ao estrangeirizar um texto, o tradutor está possibilitando a representação da diferença, o reconhecimento da alteridade. A domesticação, por sua vez, segue o caminho oposto, o de apagar as marcas estrangeiras numa tentativa de deixar o texto o mais natural possível, como se se tratasse de um texto escrito em língua doméstica, sem apresentar vestígio das diferenças interculturais.

Como recursos de estrangeirização, usamos principalmente: a conservação dos nomes próprios das personagens e uso de maiúsculas para designar povos antigos. Em língua italiana o uso de letra maiúscula tem valor distintivo entre povos antigos e modernos e o termo Sardi é usado no texto para referir-se aos primeiros habitantes da Sardenha. No entanto, essa distinção não existe na língua portuguesa de acordo com a nova ortografia e o uso da maiúscula é um recurso utilizado para dar destaque a uma palavra, designar altos conceitos políticos, religiosos e institucionais e estágios de nobreza, enfim, determina um elevado grau de prestígio. Com base nisso, mantivemos as iniciais maiúsculas como estratégia estrangeirizante que objetiva dar um ar heroico àquele povo fundador. Apesar de inicialmente se apresentarem nos contos traduzidos como ladrões e desordeiros, no decorrer da narrativa, os sardos tornam-se bravos guerreiros, que lutam contra os deuses para recuperar seu espaço.

\begin{tabular}{|c|c|}
\hline $\begin{array}{l}\text { "I Sardi, tanto tempo fa, facevano tutti i ladri e i } \\
\text { briganti. [...] }\end{array}$ & $\begin{array}{l}\text { "Os Sardos, muito tempo atrás, eram todos } \\
\text { ladrões e brigantes. [...] }\end{array}$ \\
\hline$[\ldots]$ ma siccome i Sardi sono cacciatori $[\ldots]$ & {$[\ldots]$ mas como os Sardos são caçadores [...] } \\
\hline $\begin{array}{l}\text { "I Sardi, in un tempo antichissimo, credevano che } \\
\text { i morti, [...] }\end{array}$ & $\begin{array}{l}\text { "Os Sardos, em um tempo muito antigo, } \\
\text { acreditavam que os mortos, [...] }\end{array}$ \\
\hline
\end{tabular}

Os nomes das personagens foram conservados por se tratar de figuras reais e como meio de aproximar o leitor do universo italiano. Optamos por deixar o nome Grazia, ao invés de substitui-lo por Graça, para que o leitor possa reconhecê-lo como um nome italiano e, em seguida, possa identificar a personagem com a escritora Grazia Deledda.

"Ci sto," dice Grazia, con la sua aria seria, concentrata, quasi triste.
- Topo - diz Grazia, com seu ar sério, concentrado, quase triste. 
No livro Italia storie, ballate e racconti, todas as personagens que servem de guia para o pequeno narrador, são representações de personalidades italianas. Esses heróis são ainda crianças, mas já refletem por gestos, desejos ou brincadeiras, suas conquistas futuras. A ideia do reflexo está bem clara nas ilustrações: a figura sombreada da criança segurando um espelho onde aparece a sua imagem já adulta.

Figura 1 - Imagens de Grazia Deledda criança e adulta, extraídas do capítulo Sardegna (p.

107) e mantidas na tradução.
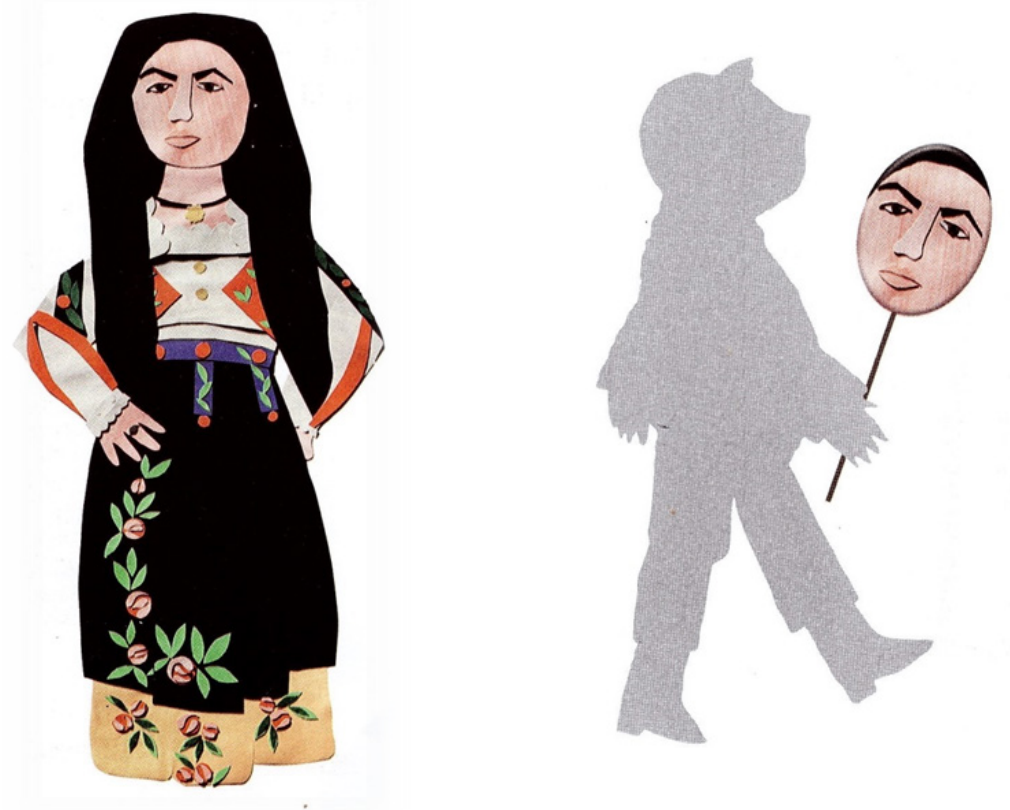

Assim, a menina Grazia, que deseja ser escritora quando crescer, será facilmente reconhecida pela criança italiana. Essa carga de prestígio, no entanto, se perde na recepção do leitor brasileiro que não reconhece a personagem.

Este foi, então, o maior desafio nesta proposta de interculturalidade. Não basta estrangeirizar, conservando vestígios da cultura estrangeira e tornando o texto ininteligível para seu público 
alvo. A proposta de interculturalidade defende, não apenas reconhecer o diferente, mas propiciar o diálogo entre as diferenças. Que recursos usar, então, para reduzir esta dificuldade de compreensão?

As notas de rodapé, considerando o público-alvo, não seriam pertinentes, pois tornarse-iam maçantes, interrompendo o ritmo de leitura e provavelmente seriam ignoradas. A solução encontrada foi nos servirmos da tradução intralingual, criando notas introdutórias para apresentar a personagem e dar informações sobre o lugar. A pequena aspirante a escritora vai lançar hipóteses sobre o surgimento dos nuragues e, em uma das histórias inventadas, os sardos precisam subir ao monte Gennargentu. Na nota, o leitor vai encontrar a definição de nurague e informações sobre o Gennargentu, logo poderá iniciar a leitura do conto familiarizado com os elementos contextuais.

\section{Você sabia?}

Figura 2 - Os nuragues

Grazia Deledda nasceu em 1871 em Nuoro, região da Sardegna. Quando cresceu ficou famosa, na Itália e no exterior, como escritora. Em 1926 ganhou o prêmio Nobel de Literatura. Morreu em Roma, aos 65 anos Você sabe o que são nuragues? Conhece o Gennargentu? O nome nurague vem da palavra nurra que significa "acúmulo", mas também "cavidade", o que descreve bem essa construção de pedras característica da Sardenha. São torres altas, formadas pelo acúmulo de pedras muito grandes, sem cimento, formando uma cúpula no alto e ocas por dentro.

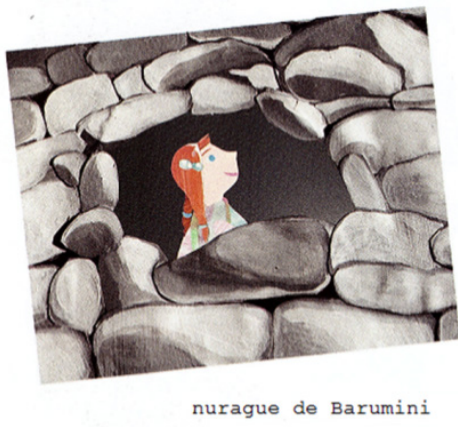

O Gennargentu é uma região montanhosa no centro da Sardenha, se situa entre as cidades de Nuoro e Ogliastra. Dentro dela estão as montanhas mais altas da ilha. (A região da Sardenha é uma ilha!)

São apresentações breves de modo a não cansar o leitor e não se estender mais que o próprio conto. Sua função é situar o leitor sobre os elementos "estranhos" no texto para que ele inicie a história contextualizado. Os elementos causadores de estranhamento têm por objetivo aproximar o leitor da cultura italiana, chamando a atenção para o diferente; no entanto, não devem se tornar obstáculos para a compreensão da narrativa. 
As ilustrações foram mantidas como recurso importante para facilitar a compreensão da história. No caso específico dos nuragues, ficaria muito difícil para o leitor brasileiro, adulto ou criança, imaginar sua estrutura sem a figura.

Figura 3 - Imagem de um nurague, extraída do capítulo Sardegna (p. 104 e 105) e mantida na tradução.

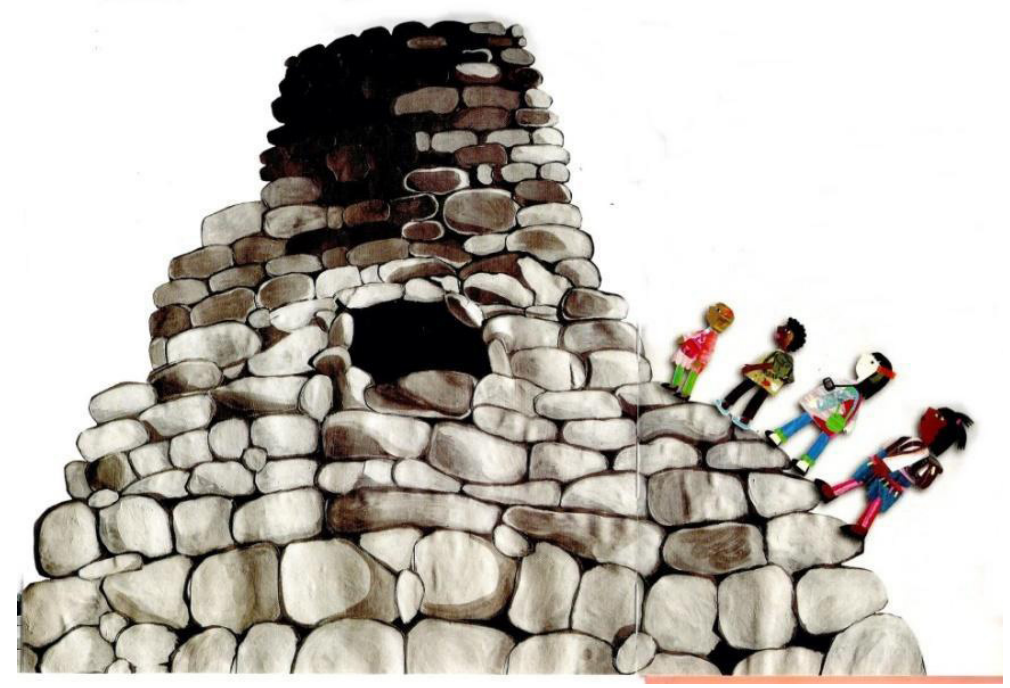

Ainda que o objetivo seja a realização de uma tradução estrangeirizadora, o texto será de algum modo domesticado. Segundo Venuti, "a tradução é uma inevitável domesticação" (1998, p. 174) e

[...] - uma tradução sempre comunica um texto estrangeiro que é parcial e alterado, ao qual se acrescentam características peculiares à língua da tradução. Na verdade, o objetivo de comunicar só pode ser atingido quando o texto estrangeiro deixa de ser inescrutavelmente estrangeiro, tornando-se compreensível de uma forma caracteristicamente doméstica (1998, p. 174). 
Assim, apresentamos elementos estrangeirizantes ao longo do texto traduzido, mas também traços de domesticação na tentativa de tornar a leitura fluida.

Essa domesticação torna-se evidente no uso de frases estruturalmente mais naturais para a cultura de chegada. Assim, a domesticação se deu, principalmente, pela adequação sintática à língua-cultura alvo. Procuramos correspondentes de expressões idiomáticas e fizemos adequações de tempos verbais para alcançar um tom mais usual em português.

Aqui um exemplo de escolha de uma forma idiomática para traduzir uma expressão usada em italiano:

Allora gli dei tirarono giù pietre giù grosse, ma siccome i Sardi sono cacciatori e hanno buon occhio, $[\ldots]$
Então os deuses jogaram pedras maiores, mas, como os Sardos são caçadores e têm olhos de lince, $[\ldots]$

A tradução trouxe, então, traços da cultura estrangeira, mas sem perder a fluidez de uma narrativa doméstica.

\section{Considerações finais}

A tradução é uma atividade interpretativa, portanto, se desenvolve a partir de um conjunto de decisões do tradutor. As escolhas tradutórias não são aleatórias, seguem uma série de elementos norteadores. Ainda que cada passo seja pensado, por ser uma prática dinâmica, a tradução está suscetível ao inesperado, para o qual o tradutor deve buscar soluções.

$\mathrm{Na}$ fase inicial desse trabalho, buscava-se levantar questões linguísticas que favorecessem um debate sobre os problemas práticos da tradução. À medida que foi sendo desenvolvido o estudo, o corpus escolhido não apresentou grandes impasses linguísticos, mas trouxe outra perspectiva, não menos interessante: a mediação cultural. A perspectiva da mediação cultural foi então decisiva para conduzir as escolhas do tradutor, incluindo sua opção por uma tradução comentada e por sua apresentação bilíngue. Ao elaborar uma pequena introdução ao capítulo, apresentando elementos fundamentais no texto, mas pouco conhecidos pelo leitor brasileiro, o tradutor, além de possibilitar o acesso a um texto escrito em língua italiana, fortalece as pontes entre as duas culturas. 


\section{Referências}

COELHO, N. N., Literatura Infantil: teoria, análise, didática. São Paulo: Moderna, 2000.

MORINI, M., La traduzione: teorie strumenti pratiche. Milano: Sironi, 2007.

PIUMINI, R., L'Autore si racconta. Milano: Franco Angeli, 2012. , Italia: storie, ballate e racconti. Livorno: Sillabe, 2013.

REISS, K,; VERMEER, H. J., Fundamentos para una teoría funcional de la traducción. Madrid: Ediciones Akal, 1996.

VERMEER, H.J., Esboço de uma Teoria da Tradução. Porto: Edições Asa, 1986.

VENUTI, L. A tradução e a formação de identidades culturais. In: SIGNORINI, I. (org.) Lingua (gem) e identidade: elementos para uma discussão no campo aplicado. Campinas: Mercado de Letras, 1998. Escândalos da Tradução: por uma ética da diferença. Trad. L. Pelegrin, L. M. Villela, M. D. Esqueda e V. Biondo. Bauru, SP: EDUSC, 2002, p. 173-200.

Recebido em 06/05/2016

Aprovado em 18/09/2016 


\section{Apêndice}

\section{Capitulo Sardegna e tradução para o português}

\section{Sardegna}

"Se è vero che da grande vuoi fare la scrittrice, inventa una storia sui nuraghi!" sfido io, sedendo affaticato su un sasso, dopo aver visitato fino alla cima il grande nuraghe di Barumini. "Anzi, siccome non si sa bene a cosa servissero, dovrai inventare una storia sulle diverse ipotesi. Ci stai?" "Ci sto," dice Grazia, con la sua aria seria, concentrata, quasi triste.

"Cominciamo."

"Alcuni pensano che i nuraghi fossero dei templi..." dico.

Grazia chiude gli occhi, stringe le labbra per dieci secondi, poi riapre gli occhi e comincia a raccontare:

"I Sardi, tanto tempo fa, facevano tutti i ladri e i briganti. Appena imparavano a camminare, cominciavano a far cose cattive. Allora gli dei che stavano sulle nuvole, presero dalle montagne delle pietre, e le tirarono giù, per punirli. Ma i Sardi, anche se le prendevano in testa, continuavano a far del male, perché avevano la testa molto dura.

Allora gli dei tirarono giù pietre giù grosse, ma siccome i Sardi sono cacciatori e hanno buon occhio, le vedevano scendere dal cielo e riuscivano a schivarle. Alla fine, gli dei tirarono dei grossi massi che, anche se visti ed evitati, scuotevano tanto il terreno che i Sardi si spaventarono, perché in questa terra non esistono $i$ terremoti. Così mandarono tre vecchi sulla cima del Gennargentu, a parlare con gli dei."

"Che dobbiamo fare, per far cessare la pioggia dei massi?"

"Smettete di fare i ladri e i briganti, e cominciate a coltivare la terra," dissero gli dei.

"Ma la terra è tutta piena dei sassi che ci avete lanciato!"

\section{Sardenha}

- Se é verdade que você quer ser escritora quando crescer, invente uma história sobre os Nuragues! - desafio, sentando exausto em uma pedra, depois de ter subido até o topo do grande nurague de Barumini. - Ou melhor, já que não se sabe pra quê serviam, você tem que inventar uma história com várias hipóteses. Você topa?

- Topo - diz Grazia, com seu ar sério, concentrado, quase triste.

- Vamos lá.

- Algumas pessoas pensam que os nuragues eram templos... - digo.

Grazia fecha os olhos, aperta os lábios por dez segundos, depois abre os olhos e começa a contar:

- Os Sardos, muito tempo atrás, eram todos ladrões e brigantes. Mal começavam a andar, já faziam coisas ruins. Então, os deuses que estavam nas nuvens, pegaram pedras das montanhas e atiraram lá embaixo, para puni-los. Mas o povo Sardo, mesmo sendo atingido na cabeça, continuava praticando o mal, porque era muito cabeça-dura.

Então os deuses jogaram pedras maiores, mas, como os Sardos são caçadores e têm olhos de lince, viam as pedras caindo do céu e conseguiam se esquivar. No final, os deuses jogaram rochas maiores, e mesmo que os Sardos pudessem vê-las e desviar delas, as pedras sacudiam tanto o chão que eles se assustaram, porque nesta terra não acontecem terremotos. Daí mandaram três velhos ao alto do monte Gennargentu, para falar com os deuses.

"O que devemos fazer para parar essa chuva de pedras?"

"Parem de agir como ladrões e brigantes e comecem a cultivar a terra", disseram os deuses.

"Mas a terra está coberta das pedras que vocês jogaram em nós!" 
"Il vostro primo lavoro, sarà quello di ripulirla." Così i Sardi, piano piano, raccolsero tutti i sassi caduti dal cielo, e li accumularono per bene: i più grossi sotto, i medi in mezzo, e i piccoli sopra. E quando li ebbero finiti, decisero di farne templi dedicati agli dei."

"Non male," osservo, con una smorfia d'apprezzamento. "Ora vediamo come te la cavi con la seconda storia. Si dice che i nuraghi non fossero dei templi, ma delle tombe..."

Grazia chiude gli occhi, stringe le labbra, e dopo dieci secondi riapre gli occhi e comincia a raccontare:

"I Sardi, in un tempo antichissimo, credevano che i morti, sepolti e sciolti nella terra, dopo un numero di anni uguale a quello dei loro capelli, si sarebbero riformati per salire in cielo.

Un giorno, uno di loro, che aveva una chioma foltissima, disse: 'E se quando io mi riformerò nella terra, fra un grandissimo numero di anni, non ricorderò più da che parte è il sopra e il sotto?

Si potrebbe lasciare un buco nella tomba: ma se poi i cinghiali e il bestiame lo riempiono? Si potrebbe seppelirmi in una capanna di legno, ma se poi qualcuno ruba la legna? Pensa e pensa, decise di farsi seppellire in una capanna di pietra, tanto robusta da non poter essere danneggiata, distrutta o rubata, e ci lasciò in cima un buco, per vedere le stelle quando si sarebbe svegliato."

"Non male!" dico, ammirato. "E adesso, vediamo cosa racconti, se i nuraghi non erano né templi né tombe, ma fortezze..."

Grazia, seria seria, chiude gli occhi, stringe le labbra, e dopo dieci secondi comincia a raccontare.
"A primeira tarefa de vocês será limpá-la!" Assim os Sardos, pouco a pouco, recolheram todas as pedras caídas do céu, empilharam-nas corretamente: as maiores em baixo, as médias no meio e as pequenas em cima. E quando terminaram decidiram fazer templos dedicados aos deuses.

- Nada mal, eu disse com ar de aprovação. Agora, vejamos como você se sai com a segunda história. Se diz que os nuragues não eram templos, eram tumbas...

Grazia fecha os olhos, comprime os lábios, e dez segundos depois abre os olhos e começa a contar:

- Os Sardos, em um tempo muito antigo, acreditavam que os mortos, sepultados e desfeitos na terra, depois de um número de anos correspondente ao tempo que cresceram seus cabelos, seriam refeitos para subir ao céu.

Um dia, um deles, que tinha uma imensa cabeleira, disse: "E se quando eu me refizer na terra, daqui a muitos anos, eu não lembrar mais onde é em cima e onde é embaixo?

Poderiam deixar um buraco na tumba, mas se depois os javalís e o gado o tapassem? Poderiam me sepultar em uma cabana de madeira, mas se depois alguém roubasse a madeira?" Pensa mais um pouco e decide que gostaria de ser enterrado em uma cabana de pedras, tão resistente que não pudesse ser danificada, destruída ou roubada, e em cima deixaria um buraco para que pudesse ver as estrelas quando acordasse.

- Nada mal! digo admirado. E agora, vejamos o que você vai contar, se os nuragues não fossem nem templos, nem tumbas, mas fortalezas...

Grazia, muito séria, fecha os olhos, comprime os lábios e dez segundos depois começa a contar. 